\title{
Thermal Transformation of Birnessite (OL) Towards Highly Active Cryptomelane (OMS-2) Catalyst for Soot Oxidation
}

\author{
T. Jakubek ${ }^{1}$. C. Hudy ${ }^{1}$ J. Gryboś ${ }^{1} \cdot$ H. Manyar ${ }^{2} \cdot$ A. Kotarba ${ }^{1}$
}

Received: 29 January 2019 / Accepted: 17 May 2019 / Published online: 30 May 2019

(c) The Author(s) 2019

\begin{abstract}
A layered potassium-manganese oxide, birnessite $\left(\mathrm{OL}: \mathrm{KMn}_{4} \mathrm{O}_{8}\right)$ was subjected to long-term post-calcination thermal treatment aimed at stimulating its activity in catalytic soot oxidation. The $12 \mathrm{~h}$ thermal treatment at several temperatures $\left(425,500,550\right.$ and $\left.650{ }^{\circ} \mathrm{C}\right)$ in atmospheric conditions resulted in the swift transformation of the layered material into the tunnel-shaped octahedral molecular sieve cryptomelane (OMS-2: $\left.\mathrm{KMn}_{8} \mathrm{O}_{16}\right)$. The obtained materials were thoroughly characterized using powder X-ray diffraction, Raman spectroscopy, $\mathrm{N}_{2}$-BET specific surface area analysis, and transmission electron microscopy techniques. With increasing temperature of thermal treatment, the concentration of OMS-2 increased, which was confirmed by Rietveld analysis, and dominated the material properties, notably the lowering of work function of the catalysts $(\Delta \phi=0.2$ and $0.4 \mathrm{eV}$ in air and vacuum, respectively). The obtained results reveal the high catalytic activity of the OMS-2 formed from the thermal transformation of the OL material compared to both the parent OL material and the uncatalyzed soot oxidation reaction. The achieved catalytic activity showed direct correlation with the temperature of pretreatment, with the most active catalyst being calcined at $550{ }^{\circ} \mathrm{C} / 12 \mathrm{~h}$, and lowering the temperature of $50 \%$ soot conversion $\left(\mathrm{T}_{50 \%}\right)$ by spectacular $150{ }^{\circ} \mathrm{C}$ in loose contact. The catalytic activities were found to correlate well with the work function (low work function-high catalytic activity), confirming the electron transfer from the catalyst surface to oxygen molecule as the important step in the soot oxidation mechanism over mixed potassium-manganese oxides. The beneficial effect of thermal pre-treatment was found to last over multiple runs, maintaining a $\mathrm{T}_{50 \%}$ lower by $100{ }^{\circ} \mathrm{C}$ compared to the untreated parent material. The obtained results indicate the importance of the temperature treatment for the catalytic performance of potassium promoted transition metal oxides as catalytically active phases for efficient soot removal in the conditions present in combustion engine exhaust gases.
\end{abstract}

\section{Graphical Abstract}

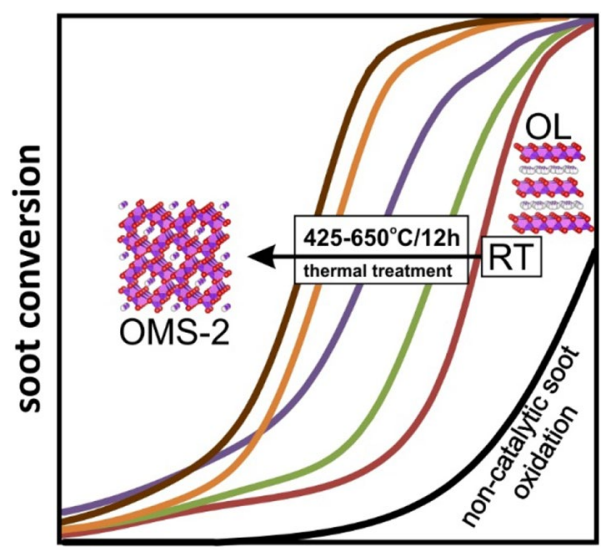

temperature

Extended author information available on the last page of the article 
Keywords Manganese oxide $\cdot$ Birnessite $\cdot \mathrm{OL} \cdot$ Cryptomelane OMS- 2 - Soot combustion $\cdot$ Diesel exhaust

\section{Introduction}

For the last half-century, one of the most pressing issues facing society is the intensified release of soot particles derived from the incomplete combustion of fuels, especially from automobile sources such as vehicles powered by combustion engines. Soot particles, because of their nano and micro size, may easily enter into the body through the skin or lungs and show mutagenic and carcinogenic properties [1, 2]. Soot may also contain additional pollutant fractions, such as polycyclic aromatic hydrocarbons (PAH), nitro-PAH and soluble organic fractions (SOF) [3], condensed onto the surface. Therefore, strict standards for particulate matter (PM) emission from combustion engines have been introduced, stimulating research aimed at the abatement of particulate pollution [4].

Diesel particulate filters (DPF) and catalytic converters are known for their effectiveness in reducing the emission of pollutants (soot, PAH, SOF) into the environment. The combustion temperature of many pollutants, such as soot $\left(550-650{ }^{\circ} \mathrm{C}\right)$, is much higher than the temperature of exhaust gases and would normally damage the systems meant for their abatement $[3,5]$. Therefore, both DPF's and catalytic converters make use of catalytic materials, which lower the temperature of combustion of the pollutants passing through the system to more manageable temperatures (between 150 and $400{ }^{\circ} \mathrm{C}$ ) [6, 7]. The efficiency of soot particles removal in CDPF (catalytic diesel particulate filter) systems highly depends on the number of points of contact between particles of soot and the catalyst. Therefore, literature describes several modes of experiments, which are performed to best simulate the different contact modes: "tight" contact represents a simulation mode, where the number of contact points is the highest, "loose" contact refers to conditions more closely resembling those that occur in the diesel engine, without as many contact points as in the previous contact mode [8].

The most prominently used commercial catalysts are based on noble metals (Pt, Pd, Rh) dispersed over supports (ceria, alumina) $[9,10]$. The price and availability of these materials increasingly motivates the search for competitive alternatives. Among them, the transition metal oxide ( $\mathrm{Fe}, \mathrm{Co}, \mathrm{Cr}, \mathrm{Cu}$, and $\mathrm{Mn}$ ) based systems are promising candidates, as they are reported to act as catalytically active phases in soot combustion [11-16]. The catalytic activity of these catalysts may further be augmented by the application of promoters such as alkali [17-19]. The electro-donor properties can be tuned through either bulk or surface promotion by alkali cations [20]. This promotes the electron transfer from the catalyst to oxygen, forming reactive oxygen species
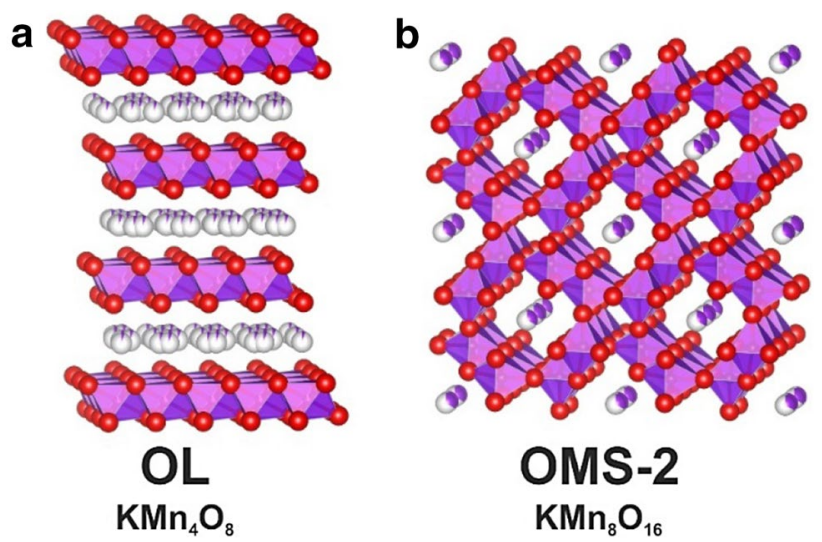

Fig. 1 Structures of the layered OL and the tunneled OMS-2 potassium-manganese-oxide catalysts

(ROS), such as $\mathrm{O}_{2}{ }^{2-}, \mathrm{O}_{2}^{-}$and $\mathrm{O}^{-}$, at the catalyst surface. Alkali bulk promotion of transition metal oxides may be considered as the process of nanostructuration, in which the heterocations force the modification of the original oxides structure, forming tunnels and layers.

Among manganese oxides, birnessite and cryptomelane are often the subjects of intense research due to their high catalytic activity in numerous reactions [21-27]. The high reactivity of both phases can be assigned to a combination of several features, such as beneficial porous structure, redox properties due to the mixed valence framework, and high oxygen mobility [22, 28-30]. Octahedral layered birnessite (OL-Fig. 1a) is a phyllomanganate-type layered oxide, comprised of sheets of edge-sharing $\mathrm{MnO}_{6}$ octahedra [31]. The interlayer space may contain a range of monovalent (alkali) or bivalent cations as well as water $[32,33]$. Cryptomelane, a hollandite type manganese oxide, is a nanoscale alkali doped manganese octahedral molecular sieve (OMS-2-Fig. 1b), in which the $\mathrm{MnO}_{6}$ octahedra build a three-dimensional, tunneled structure, nanostructured mainly by alkali cations [22]. The type and concentration of intercalated cations stabilize the layered or tunneled structure of birnessite or cryptomelane, with their charge offset by the oxidation state of the manganese in the octahedra, where the manganese cations can easily change their oxidation state from $\mathrm{Mn}^{4+}$ to $\mathrm{Mn}^{3+}$. Both structures facilitate the mobility of the enclosed alkali cations. With increasing temperature this mobility can be observed in the following processes: diffusion in the tunnels/layers, segregation on the surface and desorption from the surface in the highest temperatures $[34,35]$. Therefore, the temperature treatment of the $\mathrm{K}-\mathrm{Mn}-\mathrm{O}$ mixed oxides can have a strong implication on their final structure and thus the catalytic properties.

The transformation of OL to OMS-2 has been noted to occur during thermal and hydrothermal treatments. Hydrothermal treatment is known to stimulate the OL to OMS-2 
transformation, either through the removal of the surplus potassium cations or introduction of transition metal cations $[36,37]$. Nonetheless, some cations must be present to stimulate growth of the tunnel structure, as complete removal of intra-layer cations leads to formation of nsutite from birnessite, while the presence of $\mathrm{K}^{+}$was found to promote the transformation to OMS-2 [38]. The calcination of potassium containing OL yields pure OMS-2, whereas substitution of potassium with transition metals cations of adjustable oxidation states may lead to the framework-doping of OMS-2 [39-42].

The aim of this paper was to follow the thermal transformation of OL to OMS-2 through post-calcination thermal activation $\left(425^{\circ} \mathrm{C}, 500{ }^{\circ} \mathrm{C}, 550{ }^{\circ} \mathrm{C}\right.$, and $\left.650{ }^{\circ} \mathrm{C}\right)$ in the context of stimulating catalytic activity in soot combustion. The studies put specific focus on determining the changes of morphology, structure, electron-donor properties and catalytic activity, revealing the beneficial transition of layered OL to the more active tunneled OMS-2. Such investigation will aid in rational design of cheap and efficient catalysts for soot oxidation, with properties which can be optimized via the appropriate thermal pre-treatment.

\section{Experimental}

\subsection{Materials}

K-birnessite (OL) was prepared by a sol-gel method. In a typical synthesis, a $1.5 \mathrm{M}$ solution of glucose was added to $0.3 \mathrm{M}$ solution of potassium permanganate under vigorous stirring. Afterward, the catalyst was dried at $80^{\circ} \mathrm{C}$ overnight and subsequently calcined at $450^{\circ} \mathrm{C}$ for $2 \mathrm{~h}$. The series of thermally modified catalysts were obtained by dividing the product into even batches, which were treated for $12 \mathrm{~h}$ in various temperatures $\left(425,500,550\right.$, and $\left.650^{\circ} \mathrm{C}\right)$ under atmospheric conditions.

\subsection{Methods}

The X-ray diffraction was recorded by a Rigaku MiniFlex powder diffractometer with $\mathrm{Cu} \mathrm{K} \alpha$ radiation at $10 \mathrm{~mA}$ and $10 \mathrm{kV}$, step scans of $0.02^{\circ}$ and counting time of $3 \mathrm{~s}$ per step. Rietveld analysis of the registered X-ray diffraction patterns was carried out using the MAUD software [43]. The analysis was performed within the Bragg-Brentano geometry, with the goniometer radius equal to $150.0 \mathrm{~mm}$ and equatorial and axial slits of $1.25^{\circ}$, for both arms of the device.

The Raman spectra were measured in ambient conditions using a Renishaw InVia spectrometer equipped with a Leica DMLM confocal microscope and a CCD detector, with an excitation wavelength of $785 \mathrm{~nm}$. The laser power at the sample position was $1.5 \mathrm{~mW}$ with a magnification of $20 \times$ and a focus of $25 \%$. The Raman scattered light was collected over 9 runs in the spectral range of $100-900 \mathrm{~cm}^{-1}$.

TEM images were obtained using a Philips Tecnai F20D microscope with a field emission gun. The accelerating voltage was $200 \mathrm{kV}$ and the resolution $0.2 \mathrm{~nm}$. Samples were prepared by dispersing in methanol and sonicating for $15 \mathrm{~min}$. They were dispersed on holey carbon film copper grids.

For evaluation and comparison of electron-donor properties, the measurements of work function (or more specifically contact potential difference (CPD)) were conducted by means of a Kelvin probe (McAllister KP6500). A stainlesssteel electrode $\left(\mathrm{d}=3 \mathrm{~mm}, \phi_{\text {reference }}=4.32 \mathrm{eV}\right)$ was used as a reference. Work function value is determined by the following equation: $\phi_{\text {sample }}=\phi_{\text {reference }}-\mathrm{CPD}$. For each measurement, approx. $0.1 \mathrm{~g}$ of each sample was pressed under $6 \mathrm{MPa}$ for $1 \mathrm{~min}$ to form a pellet. The procedure of a typical measurement was as follows: the surface of the investigated sample was standardized by the thermal pre-treatment in $400{ }^{\circ} \mathrm{C}$ for $15 \mathrm{~min}$ in vacuum $\left(10^{-6} \mathrm{~Pa}\right)$ to desorb the surface contaminants. Afterward, the sample was cooled and the CPD was measured at $150{ }^{\circ} \mathrm{C}$ without exposure to air. In order to test the influence of the thermal treatment on work function, after the surface standardization, the untreated catalysts were subjected to in situ temperature treatment at different temperatures $\left(300,400,425,500,550\right.$ and $\left.650{ }^{\circ} \mathrm{C}\right)$ for a total of $105 \mathrm{~min}$. After each heating interval, the sample was cooled to $150{ }^{\circ} \mathrm{C}$ for measurement.

The activity of all synthesized and thermal-treated catalysts was determined by the temperature-programmed oxidation (TPO) of soot. In this case, model soot-Printex 80 Degussa-was mixed with the catalyst with a 1:8 mass ratio by mixing in an Eppendorf tube by shaking for $10 \mathrm{~s}$ following the loose contact method. A quartz fixed-bed reactor was heated from RT to $700{ }^{\circ} \mathrm{C}$ at $10{ }^{\circ} \mathrm{C} / \mathrm{min}$ while a gas mixture of $5 \% \mathrm{O}_{2}$ in $\mathrm{He}$ was passed over at a rate of $60 \mathrm{ml} / \mathrm{min}$. The progress of the reaction was tracked in situ by a quadrupole mass spectrometer SRS RGA200 by monitoring the concentration of the main reagents (lines for $\mathrm{m} / \mathrm{z}=18\left(\mathrm{H}_{2} \mathrm{O}\right), 28\left(\mathrm{~N}_{2} /\right.$ $\mathrm{CO}), 32\left(\mathrm{O}_{2}\right)$ and $\left.44\left(\mathrm{CO}_{2}\right)\right)$.

\section{Results}

Diffractograms obtained for the investigated samples are shown in Fig. 2a together with the appropriate references. Their examination revealed the initial diffraction lines belonging to $\mathrm{OL}$ in the untreated sample and their subsequent disappearance in lieu of characteristic maxima of OMS-2 upon prolonged thermal treatment. The OL catalyst and the forming OMS-2 were indexed in the $R^{-} \mathrm{m}$ (ICSD152,290 [44]) and $I 4 / m$ (ICSD-59159 [45]) space groups, respectively. Rietveld analysis quantified the concentration 

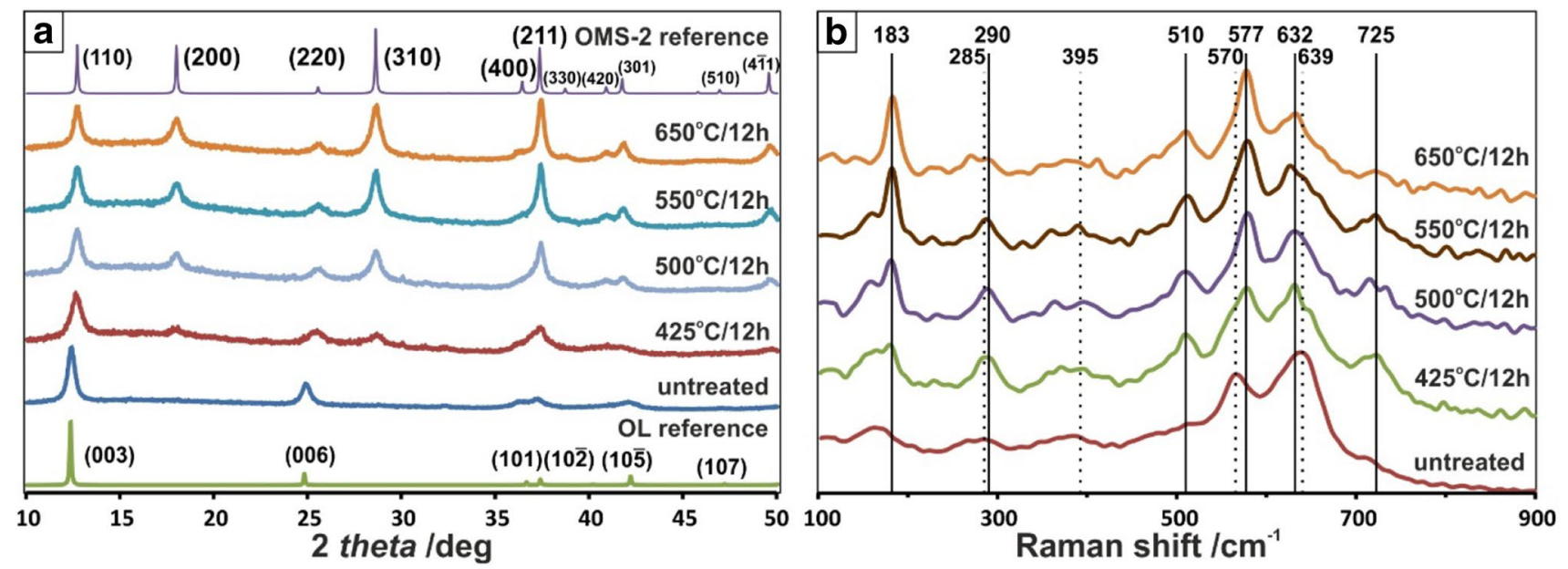

Fig. 2 a XRD patterns of the investigated OL catalysts calcined at different temperatures, b Raman spectra of the thermally treated potassiummanganese-oxide catalysts (dotted lines represent OL, solid lines represent OMS-2)

Table 1 Rietveld analysis and specific surface area of the thermally treated potassium-manganese-oxide catalysts

\begin{tabular}{llll} 
OL content/\% & OMS content/\% & $\begin{array}{l}\text { Amorph. } \\
\text { content/\% }\end{array}$ & $\mathrm{SSA} / \mathrm{m}^{2} / \mathrm{g}$ \\
\hline 65.27 & 1.13 & 33.6 & 16 \\
28.47 & 71.53 & 0 & 36 \\
13.81 & 86.19 & 0 & 20.6 \\
3 & 96.99 & 0 & 22 \\
1.23 & 98.77 & 0 & 10 \\
\hline
\end{tabular}

of the constituent phases. The results are presented in Table 1 . After prolonged treatment at $425{ }^{\circ} \mathrm{C}$ the catalyst contained a majority of OMS-2, which only increased with higher temperatures.

At $\sim 550{ }^{\circ} \mathrm{C}$ the catalyst is almost purely comprised of OMS-2.

The measured Raman spectra of the tested catalysts with marked identifiable bands can be found in Fig. $2 b$. The spectrum of the untreated catalyst shows typical bands for OL. The two most prominent bands at 570 and $639 \mathrm{~cm}^{-1}$ can be assigned to vibrations of the tetragonal structure in the interstitial space of the tunnels. The first vibration is caused by the movement of oxygen atoms relative to the manganese atoms along the $\mathrm{MnO}_{6}$ octahedral chain. The movement of oxygen in a perpendicular direction to the chain is the source of the latter band. Literature depicts broad bands near $\sim 285$ and $\sim 395 \mathrm{~cm}^{-1}$ assignable to the vibrational mode of $\mathrm{K}-\mathrm{O}$ bonds within the interlayer space, which can be discerned on the spectrum [46-49]. The spectra of the thermally treated catalysts show the visible transformation of OL to OMS-2, although both nanostructured manganese oxides exhibit similarly placed bands. The most characteristic bands for OMS-2 can be found at 577 and $632 \mathrm{~cm}^{-1}$ and assigned to the same vibrations as in the case of OL. As the main building blocks of the OL and OMS-2 structures are constituted of $\mathrm{MnO}_{6}$ octahedral chains, the $\mathrm{Mn}-\mathrm{O}$ vibrations being of the same nature are over imposed. However, due to the different local symmetry (layered vs tunneled) the intensities can be used to determine the transformation.

The band at $183 \mathrm{~cm}^{-1}$ can be assigned to the translational movement of the $\mathrm{MnO}_{6}$ octahedra. The remaining bands (290, 510 and $730 \mathrm{~cm}^{-1}$ ) are also characteristic for OMS-2 as described elsewhere $[46,50]$. The most obvious change following the thermal transformation is the lowered intensity of the OL band near $639 \mathrm{~cm}^{-1}$ and the increased intensity of the OMS-2 bands at 183 and $577 \mathrm{~cm}^{-1}$. This follows the decrease of $\mathrm{Mn}-\mathrm{O}-\mathrm{Mn}$ vibrations in the interlayer direction and the increase in vibration in the interstitial space of the tunnels. All changes are gradual and become more prominent with the increased temperature.

The specific surface area of the investigated samples (Table 1) showed an initial increase and subsequent lowering of specific surface area. The increase can be attributed to the formation of OMS-2 nanorods and the reorganisation of the amorphous phase into an organised structure, while the subsequent loss of surface area could be due to sintering. As demonstrated elsewhere, the surface area of the alkalipromoted catalysts is not the determining factor for high activity in soot combustion. The more important parameter is the electronic factor, which is known to play a primary role over the number of catalyst-soot contacts, which are proportional to the surface area [21, 22]. The low work function of the alkali-containing catalyst facilitates the formation of $\mathrm{O}_{2}^{-}$(oxygen activation) via the electron transfer. 


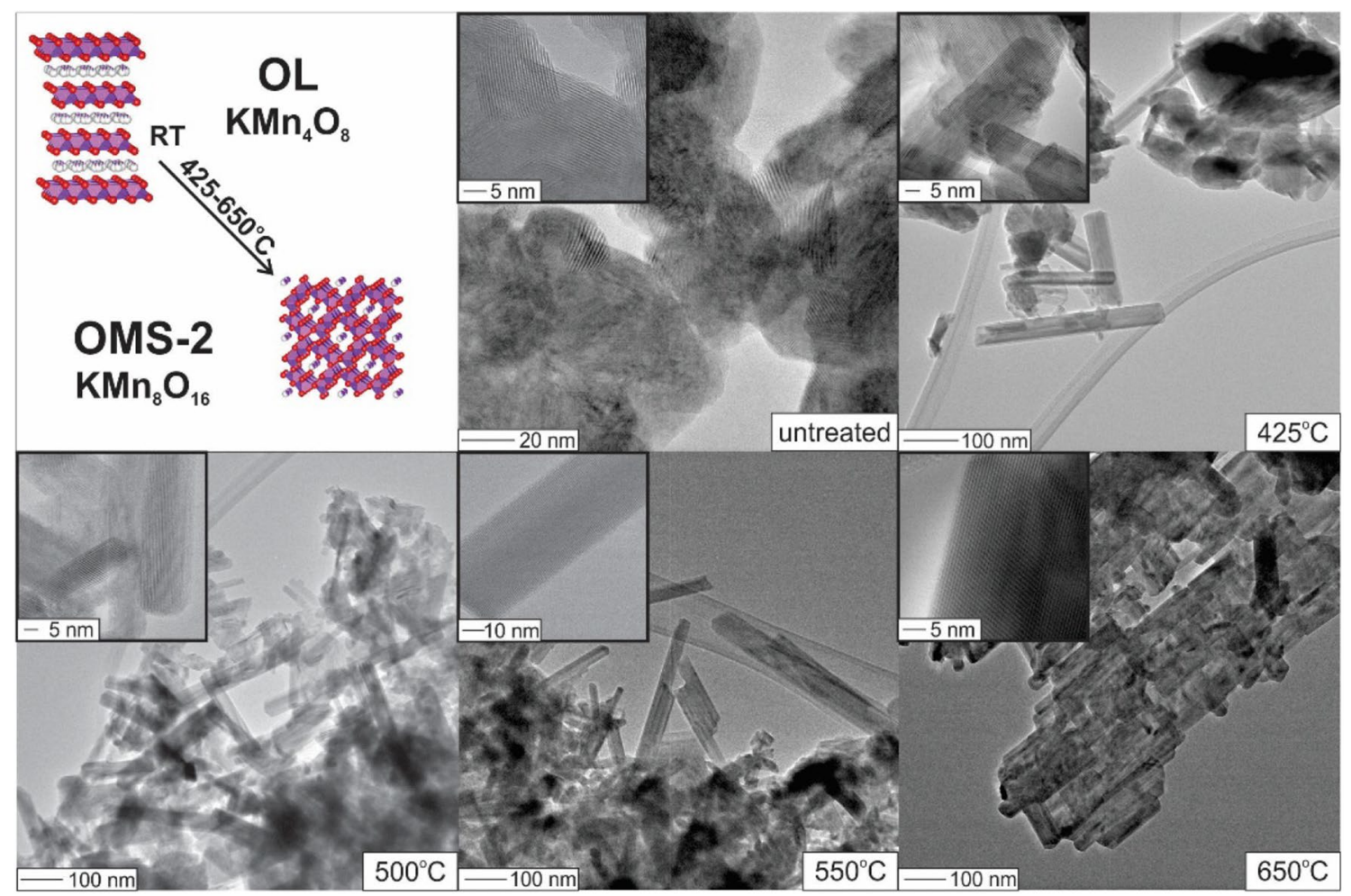

Fig. 3 TEM images of the untreated and thermally treated catalysts (inserts contain higher resolution images)

Fig. 4 Effect of thermal treatment on the work function of OL: $\mathbf{a}$ in situ heating in the Kelvin probe, $\mathbf{b}$ external heating in a furnace for $12 \mathrm{~h}$

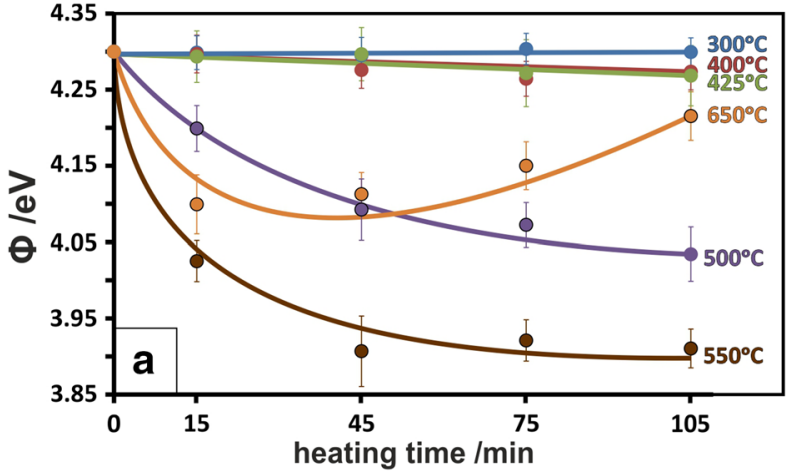

The series of catalysts treated at various temperatures for $12 \mathrm{~h}$ as well as the untreated sample were thoroughly examined using TEM (Fig. 3). The analysis revealed the irregular shape and plate-like morphology of the untreated catalyst, which is consistent for many OL catalysts. A d-spacing of $0.63 \mathrm{~nm}$ can be determined, which was not observed for the treated catalysts. Starting with the catalyst treated at $425{ }^{\circ} \mathrm{C}$, the presence of nanorods is clearly visible. The measured $\mathrm{d}$-spacings for the treated catalysts include $0.69 \mathrm{~nm}$ and $0.49 \mathrm{~nm}$, which in literature correspond to the 110 and 200 facets of OMS-2. With increasing treatment temperature, the amount of nanorods found is increased and their arrangement is changed. At lower temperatures the nanorods contain greater space between them, while at higher temperature the nanorods are clustered together, complementing the SSA analysis.

The untreated catalyst was subjected to thermal treatment in the Kelvin Probe apparatus to follow the effect on work function (Fig. 4a). At low temperatures (300, 400 and $425^{\circ} \mathrm{C}$ ) little to no change of work function was observed. With higher temperatures $\left(500,550,650{ }^{\circ} \mathrm{C}\right)$ the work function was found to be lowered. The effect continued and was found to plateau $\left(500,550^{\circ} \mathrm{C}\right)$ or be reversed, returning to higher work functions $\left(650^{\circ} \mathrm{C}\right)$. In the case of the catalyst treated at 500 and $550{ }^{\circ} \mathrm{C}$ the lowered $\phi$ can be attributed to the migration of potassium cations from within the tunnels 


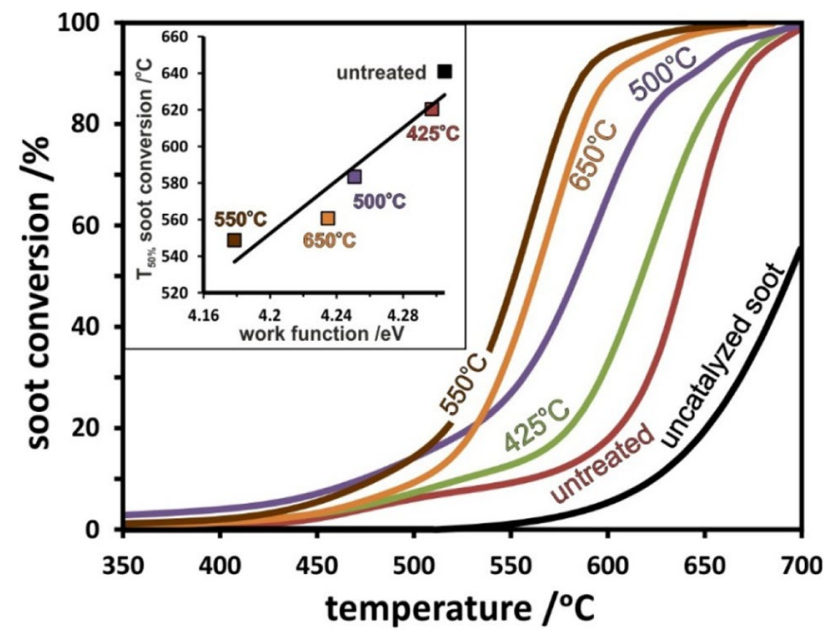

Fig. 5 Soot conversion over catalysts treated for $12 \mathrm{~h}$ at chosen temperature and correlation between catalytic activity $\left(\mathrm{T}_{50 \%}\right.$ of soot conversion) and work function of catalysts thermally treated for $12 \mathrm{~h}$ (insert)

to the outermost surface as well as the release of surface oxygen. Segregation of potassium at the surface, as well as oxygen release, are known to cause the decrease in work function value [51, 52]. Both processes are not observed at lower temperatures, during which the mobility of cations is restricted to the layers or tunnels of the material.

At the higher temperature $\left(650{ }^{\circ} \mathrm{C}\right)$ the $\phi$ changes are caused by competition of two interlaced processes: cation migration to the surface and subsequent thermal desorption. The first is responsible for the decrease of $\phi$ while the latter, causing the drop in potassium surface coverage, increases it [22]. Due to high potassium desorption flux at high temperature, in order to avoid contamination of the Kelvin probe vacuum chamber, the samples calcined for $12 \mathrm{~h}$ were measured after ex situ calcination in a furnace. The results follow a similar trend, with heat treatment tending to lower $\phi$ (Fig. 4b).

As expected, the $12 \mathrm{~h}$ thermal treatment affected the catalytic activity of the materials in loose contact with soot (Fig. 5). All tested samples were found to be catalytically active compared to the uncatalyzed soot oxidation reaction. The graph depicting soot conversion follows the sequence observed in the work function tests, with low-temperature modification being less active (higher $\phi$ ) and high-temperature treatment allowing for significant improvement of catalytic activity (lower $\phi$ ). Compared to the uncatalyzed reaction the use of the untreated catalyst lowered the temperature of $50 \%$ soot conversion by $\sim 50{ }^{\circ} \mathrm{C}$, while the most active catalyst lowered the soot oxidation temperature window by a spectacular $\Delta \mathrm{T}_{50 \%}=150{ }^{\circ} \mathrm{C}$. In the Fig. 5 insert, a correlation between work function and catalytic activity is presented. The higher catalytic activity is observed for the

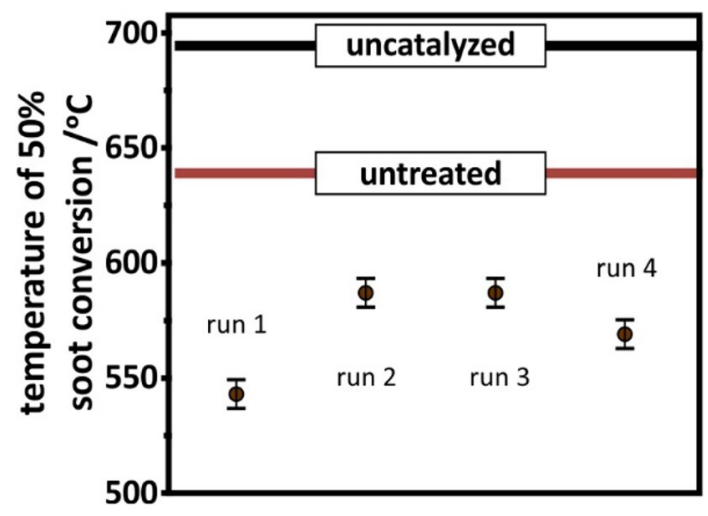

Fig. 6 Stability of catalytic activity of catalyst calcined at $550{ }^{\circ} \mathrm{C} / 12 \mathrm{~h}$ over subsequent tests

catalysts with lower work function, which were treated in higher temperatures. The found correlation has important practical meaning, as it points at a moderate thermal pretreatment of $550^{\circ} \mathrm{C}$ as the most beneficial for preparing the highly active catalyst. Furthermore, the increased activity with low work function reveals the main reaction pathway of soot oxidation over these materials. The low work function facilitates electron transfer from the catalyst surface to the oxygen molecule. As a result, reactive oxygen species (ROS), such as $\mathrm{O}_{2}{ }^{2-}, \mathrm{O}_{2}^{-}$and $\mathrm{O}^{-}$are formed at the catalyst surface, which is beneficial for the oxidation reaction. It is also worth noting, that the total transformation into OMS-2 results in a slightly less active material while the most active catalyst contains a majority of OMS-2 phase with a minor amount of OL.

The stability of the catalyst treated at $550{ }^{\circ} \mathrm{C}$ was ascertained by performing multiple tests on the same sample over consecutive runs in loose contact. As presented in Fig. 6, the initial catalytic test is always the most active (run 1), lowering the $\mathrm{T}_{50 \%}$ by $100^{\circ} \mathrm{C}$ compared to the parent catalytic material (untreated catalyst). In the subsequent runs (runs 2 through 4) the activity is somewhat lower $\left(\Delta \mathrm{T}_{50 \%}=60{ }^{\circ} \mathrm{C}\right)$ but still much higher than for the untreated catalyst. These results suggest that the thermal treatment is beneficial not only for the initial catalytic activity but is sustained over time.

\section{Conclusions}

The paper follows the beneficial transformation of the layered OL towards a highly active tunneled OMS-2 potassium-manganese-oxide catalyst for soot oxidation due to thermal treatment in the temperature range of $400-650{ }^{\circ} \mathrm{C}$. With higher temperatures, the thermal treatment of OL results in the increased concentration of OMS-2, as well as the modification of morphology, surface area and the work 
function of the prepared series of catalysts. The thermal treatment strongly modifies the electro-donor properties of the catalyst gauged by the work function $(\Delta \phi=0.4 \mathrm{eV})$, and the catalytic activity in soot oxidation. The most active catalyst prepared at $550{ }^{\circ} \mathrm{C}$ over $12 \mathrm{~h}$ in air lowers the temperature of $50 \%$ soot conversion $\left(\mathrm{T}_{50 \%}\right)$ by $150{ }^{\circ} \mathrm{C}$ in loose contact compared to the uncatalyzed reaction. The increased activity was found to be stable over several catalytic runs, showing the long-term benefits of the thermal activation with the $\mathrm{T}_{50 \%}$ lowered by $100{ }^{\circ} \mathrm{C}$ compared to the parent catalytic material. The catalytic activity was found to correlate with work function, as higher catalytic activity is observed for catalysts with low work function, revealing the electron transfer from the catalyst surface to oxygen as a significant mechanistic step in soot oxidation via the formation of reactive oxygen species. The obtained results point out the significance of thermal treatment optimization of the $\mathrm{K}-\mathrm{Mn}-\mathrm{O}$ nanostructured oxides for their catalytic activity in soot oxidation.

Acknowledgements The study was supported by the Polish National Science Centre Project awarded by Decision Number UMO-2017/24/T/ ST5/00413.

\section{Compliance with Ethical Standards}

Conflict of interest The authors declare no conflict of interest.

Open Access This article is distributed under the terms of the Creative Commons Attribution 4.0 International License (http://creativeco mmons.org/licenses/by/4.0/), which permits unrestricted use, distribution, and reproduction in any medium, provided you give appropriate credit to the original author(s) and the source, provide a link to the Creative Commons license, and indicate if changes were made.

\section{References}

1. Wornat MJ, Sarofim AF (1990) Char- and aerosol-associated polycyclic aromatic compounds from coal pyrolysis: relationship between particle size and surface composition. Aerosol Sci Technol 12:832-841

2. Wei ET, Shu HP (1983) Nitroaromatic carcinogens in diesel soot: a review of laboratory findings. Am J Public Health 73:1085-1088

3. Fino D (2007) Diesel emission control: catalytic filters for particulate removal. Sci Technol Adv Mater 8:93-100

4. Neeft J, Nijhuis X, Smakman E, Michiel M, Moulijn J (1997) Kinetics of the oxidation of diesel soot. Fuel 76:1129-1136

5. Pattas KN, Stamatelos AM, Kougianos KN, Koltsakis GC, Pistikopoulos PK (1995) Trap protection by limiting A/F ratio during regeneration. SAE Trans 104:678-688

6. Neyertz CA, Banús ED, Miró EE, Querini CA (2014) Potassiumpromoted $\mathrm{Ce}_{0.65} \mathrm{Zr}_{035} \mathrm{O}_{2}$ monolithic catalysts for diesel soot combustion. Chem Eng J 248:394-405

7. Gálvez ME, Ascaso S, Tobías I, Moliner R, Lázaro MJ (2012) Catalytic filters for the simultaneous removal of soot and $\mathrm{NO}_{\mathrm{x}}$ : influence of the alumina precursor on monolith washcoating and catalytic activity. Catal Today 191:96-105
8. Fino D, Bensaid S, Piumetti M, Russo N (2016) A review on the catalytic combustion of soot in Diesel particulate filters for automotive applications: from powder catalysts to structured reactors. Appl Catal A Gen 509:75-96

9. Huang H, Xu Y, Feng Q, Leung DYC (2015) Low temperature catalytic oxidation of volatile organic compounds: a review. Catal Sci Technol 5:2649-2669

10. Hernández-Giménez AM, Castelló DL, Bueno-López A (2014) Diesel soot combustion catalysts: review of active phases. Chem Pap 68:1154-1168

11. Wei Y, Zhao Z, Li T, Liu J, Duan A, Jiang G (2014) The novel catalysts of truncated polyhedron Pt nanoparticles supported on three-dimensionally ordered macroporous oxides ( $\mathrm{Mn}, \mathrm{Fe} \mathrm{Co}, \mathrm{Ni}$, $\mathrm{Cu}$ ) with nanoporous walls for soot combustion. Appl Catal B Environ 146:57-70

12. Legutko P, Stelmachowski P, Trę̧bala M, Sojka Z, Kotarba A (2013) Role of electronic factor in soot oxidation process over tunnelled and layered potassium iron oxide catalysts. Top Catal 56:489-492

13. Fino D, Russo N, Saracco G, Specchia V (2003) The role of suprafacial oxygen in some perovskites for the catalytic combustion of soot. J Catal 217:367-375

14. Jakubek T, Ralphs K, Kotarba A, Manyar H (2019) Nanostructured potassium-manganese oxides decorated with Pd nanoparticles as efficient catalysts for low-temperature soot oxidation. Catal Lett 149:100-106

15. Fino D, Russo N, Saracco G, Specchia V (2006) Catalytic removal of $\mathrm{NO}_{\mathrm{x}}$ and diesel soot over nanostructured spinel-type oxides. J Catal 242:38-47

16. Javier G-M, Agustín B-L, Avelina G-G (2014) Preparation, characterisation and testing of $\mathrm{CuO} / \mathrm{Ce}_{0.8} \mathrm{Zr}_{0.2} \mathrm{O}_{2}$ catalysts for $\mathrm{NO}$ oxidation to $\mathrm{NO}_{2}$ and mild temperature diesel soot combustion. Appl Catal B Environ 152-153:99-107

17. Ascaso S, Moliner R, Gálvez ME, Lazaro MJ (2013) Influence of the alkali promoter on the activity and stability of transition metal $(\mathrm{Cu} \mathrm{Co}, \mathrm{Fe})$ based structured catalysts for the simultaneous removal of soot and $\mathrm{NO}_{\mathrm{x}}$. Top Catal 56:493-498

18. Gálvez ME, Ascaso S, Stelmachowski P, Legutko P, Kotarba A, Moliner R, Lázaro MJ (2014) Influence of the surface potassium species in $\mathrm{Fe}-\mathrm{K} / \mathrm{Al}_{2} \mathrm{O}_{3}$ catalysts on the soot oxidation activity in the presence of $\mathrm{NO}_{\mathrm{x}}$. Appl Catal B Environ 152-153:88-98

19. Ura B, Trawczyński J, Kotarba A, Bieniasz W, Illán-Gómez MJ, Bueno-López A, López-Suárez FE (2011) Effect of potassium addition on catalytic activity of $\mathrm{SrTiO}_{3}$ catalyst for diesel soot combustion. Appl Catal B Environ 101:169-175

20. Jakubek T, Kaspera W, Legutko P, Stelmachowski P, Kotarba A (2015) Surface versus bulk alkali promotion of cobalt-oxide catalyst in soot oxidation. Catal Commun 71:37-41

21. Jakubek T, Kaspera W, Legutko P, Stelmachowski P, Kotarba A (2016) How to efficiently promote transition metal oxides by alkali towards catalytic soot oxidation. Top Catal 59:1083-1089

22. Stelmachowski P, Legutko P, Jakubek T, Indyka P, Sojka Z, Holmlid L, Kotarba A (2015) Emission of highly excited electronic states of potassium from cryptomelane nanorods. Phys Chem Chem Phys 17:26289-26294

23. Stelmachowski P, Legutko P, Jakubek T, Kotarba A (2018) Phase evolution and electronic properties of cryptomelane nanorods. J Alloys Compd 767:592-599

24. Selvakumar S, Nuns N, Trentesaux M, Batra VS, Giraudon JM, Lamonier JF (2018) Reaction of formaldehyde over birnessite catalyst: a combined XPS and ToF-SIMS study. Appl Catal B Environ 223:192-200

25. Santos DFM, Soares OSGP, Figueiredo JL, Pereira MFR (2018) Effect of ball milling on the catalytic activity of cryptomelane for VOC oxidation. Environ Technol. https://doi.org/10.1080/09593 330.2018 .1491639 
26. Awaluddin A, Astuti L, Linggawati A, Siregar SS, Prasetya P, Saputra L (2018) The Cu-doped cryptomelane-type octahedral molecular sieve manganese oxide synthesized by sol-gel for the degradation of methylene blue. AIP Conf Proc 2026:1-9

27. Liu Y, Zhou H, Cao R, Sun T, Zong W, Zhan J, Liu L (2019) Different behaviors of birnessite-type $\mathrm{MnO}_{2}$ modified by Ce and Mo for removing carcinogenic airborne benzene. Mater Chem Phys 221:457-466

28. Santos VP, Pereira MFR, Órfão JJM, Figueiredo JL (2010) The role of lattice oxygen on the activity of manganese oxides towards the oxidation of volatile organic compounds. Appl Catal B Environ 99:353-363

29. Peluso MA, Gambaro LA, Pronsato E, Gazzoli D, Thomas HJ, Sambeth JE (2008) Synthesis and catalytic activity of manganese dioxide (type OMS-2) for the abatement of oxygenated VOCs. Catal Today 133-135:487-492

30. Holmlid L (2002) Conditions for forming Rydberg matter: condensation of Rydberg states in the gas phase versus at surfaces. J Phys: Condens Matter 14:13469-13479

31. Hollandt KL, Walker JR (1996) Crystal structure modeling of a highly disordered potassium birnessite. Clays Clay Miner 44:744-748

32. Kuma K (1994) Crystal structures of synthetic $7 \AA$ and $10 \AA$ manganates substituted by mono- and divalent cations. Mineral Mag 58:425-447

33. Wang Y, Feng X, Villalobos M, Tan W, Liu F (2012) Sorption behavior of heavy metals on birnessite: relationship with its $\mathrm{Mn}$ average oxidation state and implications for types of sorption sites. Chem Geol 292-293:25-34

34. Delmas C, Fouassier C, Hagenmuller P (1975) Les bronzes de cobalt $\mathrm{K}_{\mathrm{x}} \mathrm{CoO}_{2}(\mathrm{x}<1)$. L'oxyde $\mathrm{KCoO}_{2}$. J Solid State Chem 13:165-171

35. Kaspera W, Wojas J, Molenda M, Kotarba A (2016) Parallel migration of potassium and oxygen ions in hexagonal tungsten bronze - bulk diffusion, surface segregation and desorption. Solid State Ionics 297:1-6

36. Fan $\mathrm{C}, \mathrm{Xu} \mathrm{L}$, Zhao W (2018) Transformation of birnessite into hollandite under the influence of silver cations in aqueous medium. J Solid State Chem 268:136-148

37. Birkner N, Navrotsky A (2017) Thermodynamics of manganese oxides: sodium, potassium, and calcium birnessite and cryptomelane. Proc Natl Acad Sci USA 114:E1046-E1053

38. Luo Y, Tan W, Suib SL, Qiu G, Liu F (2018) Dissolution and phase transformation processes of hausmannite in acidic aqueous systems under anoxic conditions. Chem Geol 487:54-62

39. Becerra ME, Arias NP, Giraldo OH, Suárez FEL, Gómez MJI, López AB (2011) Soot combustion manganese catalysts prepared by thermal decomposition of $\mathrm{KMnO}_{4}$. Appl Catal B Environ 102:260-266

40. Cai J, Liu J, Willis WS, Suib SL (2001) Framework doping of iron in tunnel structure cryptomelane. Chem A Eur J 13:2413-2422
41. Fan C, Lu A, Li Y, Wang C (2008) Synthesis, characterization, and catalytic activity of cryptomelane nanomaterials produced with industrial manganese sulfate. J Colloid Interface Sci 327:393-402

42. Jothiramalingam R, Viswanathan B, Varadarajan TK (2006) Synthesis and structural characterization of copper incorporated manganese oxide OMS-2 materials synthesized via potassium birnessite. Mater Chem Phys 100:257-261

43. Lutterotti L, Matthies S, Wenk HR, Schultz AS, Richardson JW (1997) Combined texture and structure analysis of deformed limestone from time-of-flight neutron diffraction spectra. J Appl Phys 81:594-600

44. Gaillot A, Lanson B, Drits VA (2005) Structure of birnessite obtained from decomposition of permanganate under soft hydrothermal conditions. I. Chemical and structural evolution as a function of temperature. Chem Mater 17:2959-2975

45. Vicat BJ, Fanchon E, Strobel P, Qui DT (1986) The structure $\mathrm{K}_{1.33} \mathrm{Mn}_{8} \mathrm{O}_{16}$ and cation ordering in hollandite-type structures. Acta Crystallogr Sect B 42:162-167

46. Aparna I, Joselyn D-P, Cecil KK, Edward K, Hector FG, Hui H, Abdelhamid ME-S, Prabir KD, Steven LS (2012) Water oxidation catalysis using amorphous manganese oxides, octahedral molecular sieves (OMS-2), and octahedral layered (OL-1) manganese oxide structures. J Phys Chem C 116:6474-6483

47. Julien C, Massot M, Baddour-hadjean R, Franger S, Bach S, Pereira-ramos JP (2003) Raman spectra of birnessite manganese dioxides. Solid State Ionics 159:345-356

48. Antoni H, Morales DM, Fu Q, Chen Y, Masa J, Schuhmann W, Muhler M (2018) Oxidative deposition of manganese oxide nanosheets on nitrogen- functionalized carbon nanotubes applied in the alkaline oxygen evolution reaction. ACS Omega 3:11216-11226

49. Figueira BAM, Angélica RS, da Costa ML, Pöllmann H, Schenzel K (2013) Conversion of different Brazilian manganese ores and residues into birnessite-like phyllomanganate. Appl Clay Sci 86:54-58

50. Gao T, Glerup M, Krumeich F, Nesper R, Fjellvâg H, Norby P (2008) Microstructures and spectroscopic properties of cryptomelane-type manganese dioxide nanofibers. J Phys Chem C 112:13134-13140

51. Forman R (1986) The role of oxygen in the low work function surface complex of barium on oxygen on tungsten (substrate). Appl Surf Sci 25:13-31

52. Kaspera W, Zieliński S, Kotarba A (2017) Alkali tungsten bronzes as soot oxidation catalysts: the key role of electrodonor properties of catalytic surface. Catal Commun 98:76-80

Publisher's Note Springer Nature remains neutral with regard to jurisdictional claims in published maps and institutional affiliations.

\section{Affiliations}

\section{T. Jakubek ${ }^{1} \cdot$ C. Hudy ${ }^{1} \cdot$ J. Gryboś ${ }^{1} \cdot$ H. Manyar ${ }^{2} \cdot$ A. Kotarba ${ }^{1}$}

\section{A. Kotarba}

kotarba@chemia.uj.edu.pl

1 Faculty of Chemistry, Jagiellonian University, ul. Gronostajowa 2, 30-387 Kraków, Poland
2 Theoretical and Applied Catalysis Research Cluster, School of Chemistry and Chemical Engineering Queen's University Belfast, David-Keir Building, Stranmillis Road, Belfast BT9 5AG, UK 